\title{
A submandibular nodule revealing a relapsed bladder urothelial carcinoma
}

\section{Aya Khemir ${ }^{1,2}$, Nada Mansouri'1,2, Faten Gargouri ${ }^{1,2}$, Fethi Bougrine ${ }^{1,2}$, Issam M'sakni ${ }^{1,2}$, Besma Laabidi ${ }^{1,2}$}

${ }^{1}$ Pathology Department, Military Hospital of Tunis, Monfleury, Tunis, Tunisia, ${ }^{2}$ Faculty of Medicine of Tunis, University of Tunis el Manar, Tunis, Tunisia

Corresponding author: Aya Khemir, MD, E-mail: dr.ayakhemir@gmail.com

Sir

Urothelial carcinoma metastases rarely to skin $[1,2]$. Cutaneous metastasis (CM) from bladder's transitional carcinoma counts less than $1 \%$ of all CM from all cancers $[1,3]$. Bladder cancers are in the second place ( $17 \%$ of cases) after those of kidney in genitourinary tract cancers giving CM $[1,3]$. The last may be present at the time of diagnosis or may even occur many years later after treatment [3].

A 69-year-old patient treated for infiltrating bladder transitional carcinoma many years ago presented with a submandibular nodule. The last was fortuitously discovered by the patient a month before he presented to consultation. Physical examination showed a firm subcutaneous nodule of $0.5 \mathrm{~cm}$ in diameter in the right submandibular region. At this level skin was inflamed/red and swollen. Otherwise physical examination was within normal. The described nodule above was biopsied. Microscopic examination showed infiltration of the dermis by a carcinomatous proliferation (Fig. 1). Tumor cells were arranged in small nests and clusters surrounded by a fibrous stroma. Tumor cells showed moderate nuclear atypia. Immunohistochemical staining showed positivity of tumor cells for Cytokeratin 7 and P63 (Fig. 2). Therefore, taking into consideration patient's medical history, microscopic and immunohistochemical findings the diagnosis of $\mathrm{CM}$ from urothelial carcinoma was retained.

The first case of CM from bladder carcinoma was reported in 1909 [3]. Since then many case have been reported $[1,2]$. According to cases reported in literature so far, the mean interval of time between the setting of bladder cancer and the appearance of CM is of 18 months approximately. Large tumor size and deep infiltration of the bladder wall are predictive factors of CM. However, cases of CM associated with superficial bladder carcinomas were reported [3].

The certain diagnosis is based on microscopic examination $[1,3]$. Pathologists should be aware of patient's medical history to facilitate the diagnosis and choosing appropriate immunostains if necessary especially in front of a poorly differentiated carcinoma [3]. Urothelial carcinomas express Cytokeratin 7 and

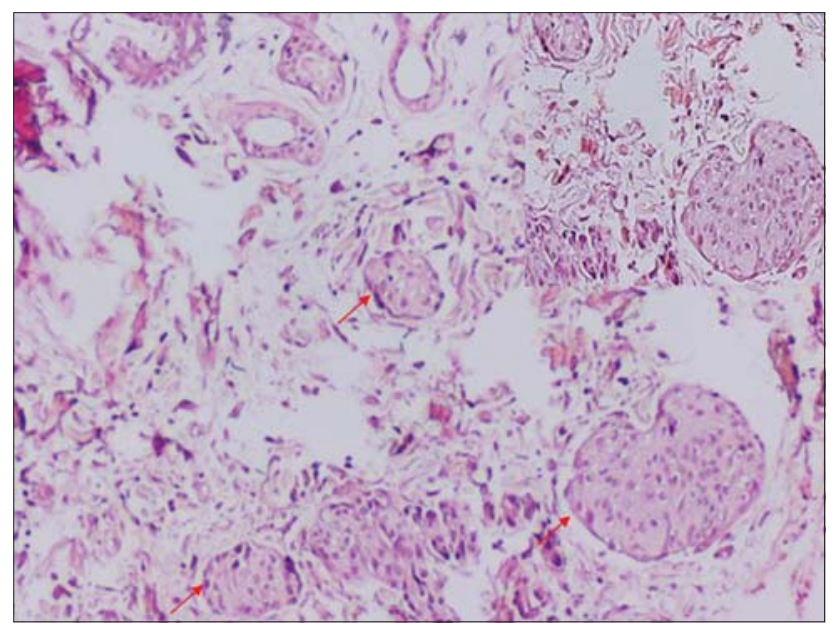

Figure 1: H\&E x40 showing infiltration of the dermis by nests of a transitional type malignant cells proliferation (red arrows) insert $\mathrm{H} \& \mathrm{E} \times 100$ Higher magnification of the carcinomatous proliferation invading the dermis showing moderate nuclear atypia of tumor cells.

\footnotetext{
How to cite this article: Khemir A, Mansouri N, Gargouri F, Bougrine F, M'sakni I, Laabidi B. A submandibular nodule revealing a relapsed bladder urothelial carcinoma. Our Dermatol Online. 2021;12(e):e10.

Submission: 04.01.2021; Acceptance: 23.04.2021

DOI:10.7241/ourd.2021e.10
} 


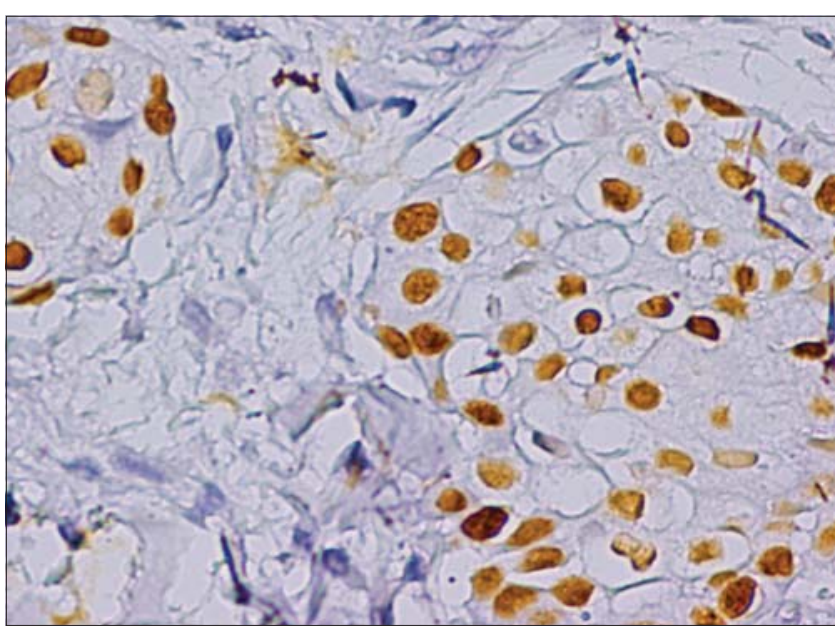

Figure 2: Cytokeratin 7 antibody staining $x 400$ showing intense and diffuse nuclear positivity of tumor cells.

Cytokeratin 20 antibodies [3]. The occurring of CM in case of bladder cancer darken the prognosis $[1,2]$. Median survival rates are less than 12 months in published cases so far [1,3]. Treatment consists of chemotherapy if the patient could bare it [1]. Total recovery was detected in $70 \%$ of cases of $\mathrm{CM}$ treated with chemotherapy. Yet, it does not improve global survival rates [3].

\section{Consent}

The examination of the patient was conducted according to the principles of the Declaration of Helsinki.

The authors certify that they have obtained all appropriate patient consent forms, in which the patients gave their consent for images and other clinical information to be included in the journal. The patients understand that their names and initials will not be published and due effort will be made to conceal their identity, but that anonymity cannot be guaranteed.

\section{REFERENCES}

1. Hasan O, Houlihan M, Wymer K, Hollowell CMP, Kohler TS. Cutaneous metastasis of bladder urothelial carcinoma. Urol Case Rep. 2020;28:101066.

2. Cohen T, Ricchiuti D, Memo M. Bladder cancer that metastasized to the skin: A unique presentation that signifies poor prognosis. Rev Urol. 2017;19:67-71.

3. Lees AN. Cutaneous metastasis of transitional cell carcinoma of the urinary bladder eight years after the primary: a case report. J Med Case Reports. déc 2015;9:102.

Copyright by Aya Khemir, et al. This is an open-access article distributed under the terms of the Creative Commons Attribution License, which permits unrestricted use, distribution, and reproduction in any medium, provided the original author and source are credited.

Source of Support: Nil, Conflict of Interest: None declared. 